\title{
BM] Global Health Association between maternal anaemia and pregnancy outcomes: a cohort study in Assam, India
}

\author{
Manisha Nair, ${ }^{1}$ Manoj K Choudhury, ${ }^{2}$ Saswati S Choudhury, ${ }^{3}$ Swapna D Kakoty, ${ }^{3}$ \\ Umesh C Sarma, ${ }^{2}$ Premila Webster, ${ }^{4}$ Marian Knight, ${ }^{5}$ On behalf of the \\ IndOSS-Assam steering committee
}

To cite: Nair M,

Choudhury MK,

Choudhury SS, et al.

Association between maternal anaemia and pregnancy outcomes: a cohort study in Assam, India. BMJ Global Health 2016;1:e000026. doi:10.1136/bmjgh-2015000026

- Additional material is published online only. To view please visit the journal (http://dx.doi.org/10.1136/ bmjgh-2015-000026).

Received 15 December 2015 Revised 10 March 2016 Accepted 11 March 2016

CrossMark

${ }^{1}$ National Perinatal

Epidemiology Unit (NPEU),

Nuffield Department of Population Health, University of Oxford, Oxford, UK

${ }^{2}$ Srimanta Sankaradeva University of Health Sciences, Guwahati, Assam, India ${ }^{3}$ F.A.A. Medical College, Barpeta, Assam, India ${ }^{4}$ Oxford School of Public Health, Oxford Deanery,

Oxford, UK

${ }^{5}$ NPEU, Nuffield Department of Population Health,

University of $0 x f o r d$,

Oxford, UK

\section{Correspondence to}

Dr Manisha Nair:

manisha.nair@npeu.ox.ac.uk

\section{ABSTRACT}

Objectives: To examine the association between maternal anaemia and adverse maternal and infant outcomes, and to assess the feasibility of conducting epidemiological studies through the Indian Obstetric Surveillance System-Assam (IndOSS-Assam).

Design: Retrospective cohort study using anonymised hospital records. Exposure: maternal iron deficiency anaemia; outcomes: postpartum haemorrhage (PPH), low birthweight, small-for-gestational age babies, perinatal death.

Setting: 5 government medical colleges in Assam. Study population: 1007 pregnant women who delivered in the 5 medical colleges from January to June 2015.

Main outcome measures: ORs with $95 \% \mathrm{Cls}$ to estimate the association between maternal iron deficiency anaemia and the adverse maternal and infant outcomes. Potential interactive roles of infections and induction of labour on the adverse outcomes were explored.

Results: 35\% ( $n=351)$ pregnant women had moderate-severe anaemia. Women with severe anaemia had a higher odds of PPH (adjusted OR ( $\mathrm{aOR}$ ) $=9.45$; $95 \% \mathrm{Cl} 2.62$ to 34.05 ), giving birth to low birthweight (aOR=6.19; $95 \% \mathrm{Cl} 1.44$ to 26.71) and small-forgestational age babies $(\mathrm{aOR}=8.72 ; 95 \% \mathrm{Cl} 1.66$ to 45.67), and perinatal death (aOR=16.42; $95 \% \mathrm{Cl} 4.38$ to 61.55). Odds of PPH increased 17 -fold among women with moderate-severe anaemia who underwent induction of labour, and 19-fold among women who had infection and moderate-severe anaemia.

Conclusions: Maternal iron deficiency anaemia is a major public health problem in Assam. Maternal anaemia was associated with increased risks of PPH, low birthweight, small-for-gestational age babies and perinatal death. While the best approach is prevention, a large number of women present with severe anaemia late in pregnancy and there is no clear guidance on how these women should be managed during labour and delivery.

\section{INTRODUCTION}

Assam, a north-eastern state in India, is reported to have a high maternal mortality

\section{Key questions}

What is already known about this topic?

- Assam, a north-eastern state in India, is reported to have high maternal and infant mortality. It has been hypothesised that iron deficiency anaemia is a major causal factor. However, there is limited research evidence of a causal relationship with maternal and neonatal mortality in Assam.

\section{What are the new findings?}

- This study was part of a pilot study conducted to assess the feasibility of establishing an Indian obstetric surveillance and research system in the state of Assam (IndOSS-Assam) and demonstrated the feasibility of using routine medical records for future prospective epidemiological studies linked to the surveillance system.

- This study showed a high prevalence of iron deficiency anaemia among pregnant women in Assam, which highlights that this is an important public health problem. Maternal anaemia was associated with increased risks of postpartum haemorrhage, low birthweight, small-forgestational age babies and perinatal death.

- The odds of postpartum haemorrhage increased 17 -fold, notably among women with moderatesevere anaemia who underwent induction of labour.

\section{Recommendations for policy}

- Clearly, the best approach is to prevent anaemia or to treat it during the antenatal period, but a large number of pregnant women in India present with severe anaemia either at the point of delivery or in the third trimester. At present, there is no clear guidance with regard to how women with severe anaemia should be managed during labour and delivery, and further studies are required to generate evidence in order to inform policy and practice.

ratio (MMR) as well as a high infant mortality rate (IMR). A report published by the Office of the Registrar General, India, estimated the MMR to be 328/100000 live 
births for the years $2010-2012^{1}$ and IMR to be $55 / 1000$ live births for the year 2011. ${ }^{2}$ It has been hypothesised that iron deficiency anaemia is a major cause of the high maternal and infant mortality in the state. Assam has the highest prevalence of iron deficiency anaemia among pregnant women (73\%, Indian National Family Health Survey 2005-2006). ${ }^{3}$ A study in one tertiary hospital in the state showed that maternal haemoglobin $(\mathrm{Hb})$ levels $<8 \mathrm{~g} / \mathrm{dL}$ were associated with increased risk of low birthweight and small-for-gestational age babies, ${ }^{4}$ but we did not find any study that examined the effects on maternal and perinatal outcomes.

Iron deficiency anaemia during pregnancy is a known risk factor for preterm birth, low birthweight and small-for-gestational age babies, ${ }^{5}$ and increases the risk of postpartum haemorrhage (PPH) ${ }^{6} \mathrm{PPH}$ is the leading cause of maternal mortality in India. ${ }^{7}$ The incidence of PPH is much higher in India compared with the rest of the world and the Registrar General of India attributes this to the high prevalence of anaemia among pregnant women. ${ }^{8}$ A study investigating the causes of neonatal deaths among the tea garden labourers in Assam reported a high prevalence of low birth weight $(43 \%)$ and preterm deliveries (34\%) in the study population, contributing to $>90 \%$ of the neonatal deaths. ${ }^{9}$

While untreated iron deficiency anaemia can itself lead to adverse outcomes, its negative effects may be aggravated by the presence of other risk factors such as infections during pregnancy (malaria, ${ }^{10}$ urinary tract infection (UTI) ${ }^{11}$ helminthic infections ${ }^{12}$ ). Additionally, studies have suggested that induction of labour is associated with increased risk of $\mathrm{PPH}^{13}{ }^{14}$ These factors could augment the adverse effects of anaemia on pregnancy outcomes. The objectives of this study were to examine the association between maternal anaemia and PPH, low birthweight, small-for-gestational age babies and perinatal death. In addition, we explored the potential interactive role of infections and induction of labour on the adverse effects of iron deficiency anaemia.

\section{METHODS}

We conducted a cohort study using anonymised hospital records of pregnant women ( $>20$ weeks of gestation) who underwent delivery in five government medical colleges and hospitals in Assam: Gauhati Medical College and Hospital (GMCH), Guwahati; Assam Medical College and Hospital (AMCH), Dibrugarh; Silchar Medical College and Hospital, Silchar; Fakhruddin Ali Ahmed Medical College and Hospital (FAAMCH), Barpeta; and Jorhat Medical College and Hospital, Jorhat. This study was part of a pilot study conducted to assess the feasibility of establishing an Indian obstetric surveillance and research system in the state of Assam (IndOSS-Assam). Details of the feasibility study are described separately. ${ }^{15}$ This retrospective study was undertaken to establish the feasibility of using routine medical records for future prospective epidemiological studies linked to the surveillance system.

A data collection form adapted from the Indian Demographic and Health Survey questionnaire and UK Obstetric Surveillance System ${ }^{16}$ was used to collect anonymous information from the hospital and antenatal records of pregnant women. Data were collected sequentially from the five study sites, for 1 month per site, over a period of 6 months (January-June 2015) to include an average of 200 women per site for an even distribution of the required sample. All women admitted to the postnatal ward of the hospital during the study month were included (until the sample size of 200 was reached) and data were collected from their hospital records by field staff from the Regional Resource Centre, Guwahati, Assam.

The primary exposure for this cohort study was maternal iron deficiency anaemia defined using the WHO criteria for moderate anaemia (pregnant women with an $\mathrm{Hb}$ level of $7-9.9 \mathrm{~g} / \mathrm{dL}$ ) and severe anaemia ( $\mathrm{Hb}$ level $<7 \mathrm{~g} / \mathrm{dL}) .{ }^{17}$ The other exposures, malaria, UTI, helminthic infections and induction of labour, were recorded on the basis of reported diagnoses by clinicians from the women's hospital and antenatal records. The primary outcomes of interest were: (1) primary PPH defined as pregnant women of 20 weeks gestation or more identified as having a blood loss of $500 \mathrm{~mL}$ or more from the genital tract within $24 \mathrm{~h}$ of birth of a baby $^{18}$ and (2) low birthweight defined as weight at birth of $<2500 \mathrm{~g}$. In addition, we examined two other secondary infant outcomes: small-for-gestational age babies and perinatal death which included stillbirths and neonatal deaths within the first week of life.

The hospital notes did not have information on $\mathrm{Hb}$ levels recorded at different gestational periods for each woman. Therefore, we included most recently recorded antenatal $\mathrm{Hb}$ concentration and noted the gestational age at which it was recorded. We tested the continuous variable 'haemoglobin level' for deviations from linearity. Fitting fractional polynomials showed the presence of a non-linear relationship of $\mathrm{Hb}$ level with the outcomes $\mathrm{PPH}$, low birthweight and small-for-gestational age babies. We therefore categorised pregnant women into three groups: mild anaemia/normal $\mathrm{Hb}$, moderate anaemia and severe anaemia.

Gender-specific z-scores and centiles for birthweightfor-gestational age were generated using the INTERGROWTH-21st tool ${ }^{19}$ for all singleton pregnancies. Infants below the 10th centile or with a z-score $<-1.28$ were grouped as small-for-gestational age.

We also collected information on known confounders and risk factors for maternal and infant morbidity and mortality including sociodemographic factors such as maternal age, body mass index (BMI), caste (social class), religion, residence, below poverty line status, women's employment status, husband's occupational status and whether he was a tea garden worker; pregnancy-related factors such as parity, previous 
caesarean section, interpregnancy interval, previous pregnancy problems, pre-existing medical problems, multiple pregnancies, number of antenatal visits, whether folic acid tablets were received and mode of delivery. BMI was calculated from the earliest available information on weight and height of pregnant women measured during the antenatal period, but we do not know the exact time point at which it was measured.

\section{Study power and sample}

India is reported to have a high incidence of $\mathrm{PPH} ;{ }^{8}$ therefore, a risk of $16 \%$ was used for estimating the sample size. For the outcome low birthweight, the reported overall incidence of $37.3 \%$ in the state ${ }^{20}$ was used for the purpose of sample size calculation. Assuming an effect size for the risk ratio to be 1.5, power as $80 \%, \alpha 5 \%$, and ratio of unexposed to exposed 2, for the above proportions of risk in the unexposed group, we estimated a sample of 230 in the exposed group for the outcome PPH and 70 in the exposed group for low birth weight. These estimates were inflated to account for cluster sampling and possible missing information to give a final estimated sample size of 980 .

\section{Statistical analyses}

We conducted an initial descriptive analysis to compare the distribution of the confounders and other risk factors across the three exposure groups and univariable analyses to examine the crude ORs for the association between exposure and outcomes. We conducted explanatory multivariable logistic regression analyses using separate models to investigate the associations of maternal anaemia with PPH, low birthweight, small-for-gestational age babies and perinatal death.

We conducted tests for interaction by fitting interaction terms for maternal anaemia and infections during pregnancy for the outcomes PPH, low birthweight and small-for-gestational age babies, and maternal anaemia and induction of labour for PPH followed by likelihood ratio tests. We found significant interaction between these variables; therefore, dummy variables were generated to ascertain the effects of these interactions on the outcomes in separate multivariable logistic regression analyses.

Tests for correlation between the independent variables showed a high correlation between parity and the interpregnancy interval; this variable was therefore not included in the multivariable model. We also found a significant correlation between husbands' employment status and below poverty line household, as well as between husbands' employment status and that of the tea garden worker; thus, husbands' employment status was excluded to improve model parsimony. The final multivariable models therefore adjusted for the following risk factors: caste, religion, residence, below poverty line status, women's employment status, tea garden worker, parity, BMI, maternal age, previous caesarean section, previous pregnancy problems, placental problems in index pregnancy, pre-existing medical problems, multiple pregnancies, number of antenatal visits, whether folic acid tablets were received, and mode of delivery. Mode of delivery was not included in the infant outcomes model as this is not likely to be causally associated.

A substantial proportion of the data was missing for BMI, parity, previous pregnancy problems and below poverty line status. We did not assume the data to be missing at random and generated proxy variables with missing as a separate group for all variables. However, we also conducted complete case analysis for all outcomes and sensitivity analyses by redistributing the missing observations into the different categories of the variables. The results of complete case analyses and sensitivity analyses did not materially differ from that of the main models other than to widen the $95 \%$ CI, except for small-for-gestational age for which results could not be obtained as the dependent variable did not vary within the severe anaemia group in complete case analysis (see online supplementary table S1).

On the basis of the sampling frame, clustering of data was at the level of the tertiary hospital which caters to the population within a definite geographical boundary. We did not consider the intraclass correlation coefficient to be high because the geographical areas that the five tertiary hospitals serve are large with a heterogeneous population. Further, the sampling used a single stage cluster design with five large clusters; thus, we employed the Hubert-White robust SEs method to account for any clustering effect. All associations were considered to be significant at a $\mathrm{p}$ value of $<0.05$ (two tailed) and all analyses were performed using Stata V.13.1, SE (StataCorp, College Station, Texas, USA).

\section{RESULTS}

Information was collected for a total of 1011 pregnant women. After excluding one woman who delivered at $<20$ weeks gestation and three women for whom information on the $\mathrm{Hb}$ level was not available, we had a sample of 1007 women (figure 1).

On the basis of the information available from the hospital records, 33 of the 1007 women $(3.3 \%)$ had a $\mathrm{PPH}$. Eleven women were reported to have a blood loss of 500-999 mL, 6 between 1000 and $1499 \mathrm{~mL}$, another 6 had $>1500 \mathrm{~mL}$ of blood loss in the first $24 \mathrm{~h}$ after delivery and for the remaining 10, estimates of blood loss were not available. In $73 \%$ of the $\mathrm{PPH}$ cases, the reported cause was uterine atony $(n=24)$; other causes included placenta praevia $(\mathrm{n}=2)$, placental abruption $(n=1)$, uterine infection $(n=2)$, tears/injuries $(n=2)$ and retained placenta $(\mathrm{n}=2)$.

We found a high prevalence ( $\mathrm{n}=263$ of the 969, 27\%) of low birthweight among live-born singleton pregnancies in the study population and a higher prevalence of small-for-gestational age $(n=409$ of the $969,42 \%)$. There were 33 perinatal deaths of the 989 singleton 
Total pregnant women for whom data was collected $=1011$

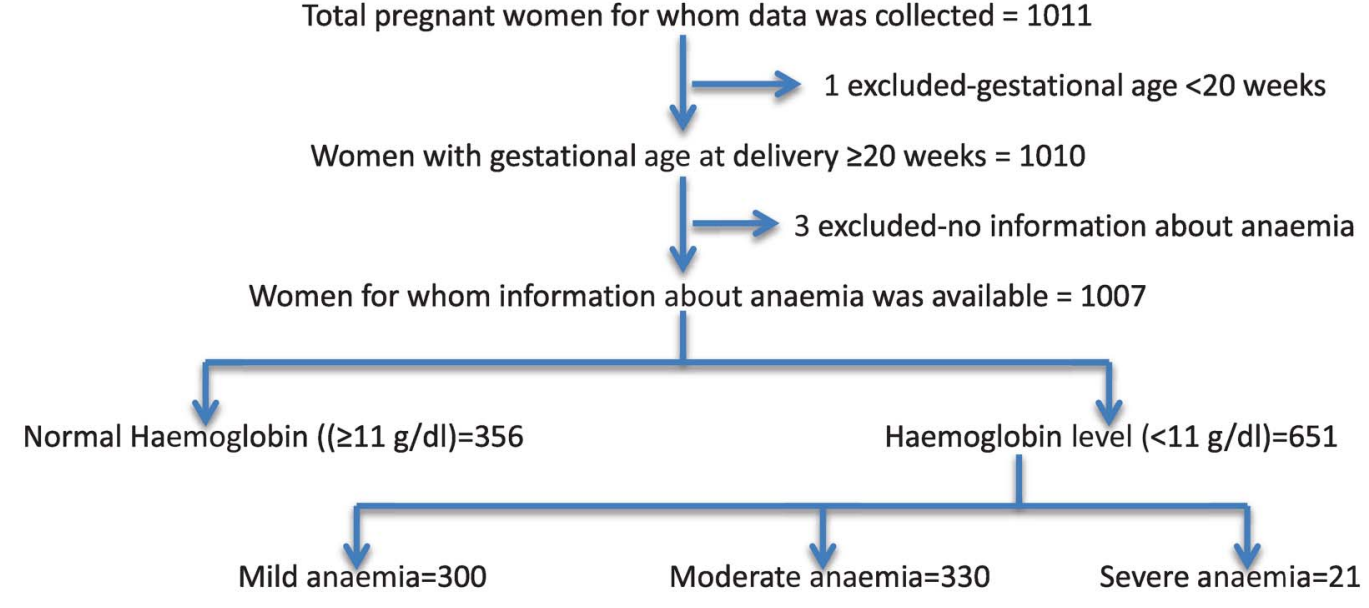

Figure 1 Flow chart to show the study population.

pregnancies (3.3\%), 20 stillbirths and 13 neonatal deaths which occurred either on the day of delivery or within 2 days of birth.

Among the 1007 pregnant women, 28\% ( $\mathrm{n}=282)$ had the most recently recorded $\mathrm{Hb}$ in the first trimester (1-12 weeks of gestation), 37\% ( $n=372)$ in the second trimester (13-27 weeks), 30\% $(\mathrm{n}=302)$ in the third trimester (28-40 weeks), and for the remaining $5 \% \quad(n=51)$ the date of $\mathrm{Hb}$ record was not available. Overall, $65.1 \%$ had mild anaemia/normal $\mathrm{Hb}$ levels (356 women with normal $\mathrm{Hb} \geq 11 \mathrm{~g} / \mathrm{dL}$, and 300 with mild anaemia $10-10.9 \mathrm{~g} / \mathrm{dL}), 32.8 \%$ had moderate anaemia $(\mathrm{n}=330)$ and $2.1 \% \quad(\mathrm{n}=21)$ had severe anaemia during the antenatal period. Just over a quarter of women $(n=141)$ received treatment for anaemia including iron supplementation, blood transfusion or other treatments (such as herbal remedies).

The sociodemographic and pregnancy-related characteristics of the women are shown in table 1. After adjusting for the sociodemographic and pregnancyrelated characteristics, we found that compared with women with mild anaemia/normal Hb level, women with severe anaemia had a more than ninefold higher odds of PPH (adjusted OR (aOR) 9.45; 95\% CI 2.62 to 34.05), a sixfold higher odds of giving birth to a low birthweight baby (aOR 6.19; 95\% CI 1.44 to 26.71), and an almost ninefold higher odds of having a small-for-gestational age baby (aOR 8.72; 95\% CI 1.66 to 45.67) (table 2). Women with moderate anaemia also had higher odds of PPH, low birthweight and small-for-gestational age babies compared with women with mild anaemia/normal $\mathrm{Hb}$ level, but the association was statistically significant only for the low birthweight outcome (table 2).

The odds of $\mathrm{PPH}$ were 17-fold higher among women who had moderate-severe anaemia and underwent induction of labour compared with women who had neither of these exposures. Similarly, the odds of PPH were almost 19-fold higher among women who had moderate-severe anaemia and infection during pregnancy compared with women who had neither of these risk factors (table 2). The associations between moderate-severe anaemia and infant outcomes, low birthweight and small-for-gestational age were observed to not vary according to the presence of maternal infection during the antenatal period. Women with severe anaemia were observed to have a 16-fold higher odds of perinatal mortality compared with women with mild anaemia/normal Hb levels (table 2).

\section{Calculated study power based on estimated prevalence of the outcomes in the study population}

The prevalence of the outcomes PPH and low birthweight was found to be lower than the figures available from the literature; therefore, we calculated the study power for each outcome on the basis of the estimated prevalence of the outcomes in the study population and the final sample. For a prevalence of $2.3 \% \mathrm{PPH}$ in the unexposed population, with 351 participants in the exposed group (ratio of unexposed (mild anaemia/ normal $\mathrm{Hb}$ ) to exposed (moderate-severe anaemia) $=1.9$ ), our study had $80 \%$ power to detect significantly an OR of 2.28 or greater associated with maternal anaemia at $\mathrm{p}<0.05$ (two-tailed). For the prevalence of $25 \%$ low birthweight babies in the unexposed population, with 351 participants in the exposed group (ratio of unexposed to exposed=1.9), our study had $80 \%$ power to detect significantly an OR of 1.29 or greater. For a prevalence of $44 \%$ small-for-gestational age babies in the unexposed group (351 participants in the exposed group, ratio of unexposed to exposed $=1.9$ ), our study had $80 \%$ power to detect significantly an OR of 1.19 or greater, and for a prevalence of $2.8 \%$ perinatal deaths in the unexposed group (351 participants in the exposed group, ratio of unexposed to exposed $=1.9$ ), our study had $80 \%$ power to detect significantly an OR of 1.16 or greater.

\section{DISCUSSION}

We were able to use the IndOSS-Assam surveillance and research system successfully to conduct this cohort study. 
Table 1 Comparison of maternal and infant characteristics across the exposure groups

\begin{tabular}{|c|c|c|c|}
\hline \multirow[b]{2}{*}{$\begin{array}{l}\text { Characteristics } \\
\text { ( } N=1007 \text {, except } \\
\text { where specified) }\end{array}$} & \multicolumn{3}{|c|}{ Maternal anaemia } \\
\hline & $\begin{array}{l}\text { Normal } \\
\text { haemoglobin/ } \\
\text { mild, } n=656 \\
\text { Frequency } \\
\text { (\%) }\end{array}$ & $\begin{array}{l}\text { Moderate, } \\
\mathrm{n}=330 \\
\text { Frequency } \\
(\%)\end{array}$ & $\begin{array}{l}\text { Severe, } \\
\mathrm{n}=21 \\
\text { Frequency } \\
(\%)\end{array}$ \\
\hline \multicolumn{4}{|l|}{ Maternal age, years } \\
\hline$<20$ & $75(11.4)$ & $29(8.8)$ & $0(0)$ \\
\hline $20-25$ & $394(60.1)$ & $204(61.8)$ & $13(61.9)$ \\
\hline $26-30$ & $149(22.7)$ & $78(23.6)$ & $6(28.6)$ \\
\hline$\geq 30$ & $37(5.6)$ & $19(5.8)$ & $2(9.5)$ \\
\hline Not known & $1(0.2)$ & $0(0)$ & $0(0)$ \\
\hline \multicolumn{4}{|l|}{$\mathrm{BMl}$ in $\mathrm{kg} / \mathrm{m}^{2}$} \\
\hline Underweight & $120(18.3)$ & $61(18.5)$ & $2(9.5)$ \\
\hline Normal & $338(51.5)$ & $172(52.1)$ & 7 (33.3) \\
\hline Overweight & $42(6.4)$ & $21(6.4)$ & $3(14.3)$ \\
\hline Obese & $11(1.7)$ & $8(2.4)$ & $0(0)$ \\
\hline Not known & $145(22.1)$ & $68(20.6)$ & 9 (42.9) \\
\hline \multicolumn{4}{|c|}{ Pregnancy-related factors } \\
\hline \multicolumn{4}{|c|}{ Parity ${ }^{\star}$} \\
\hline Nulliparous & $98(14.9)$ & $36(10.9)$ & $0(0)$ \\
\hline Multiparous & $274(41.8)$ & $184(55.8)$ & $19(90.5)$ \\
\hline Not known & $284(43.3)$ & $110(33.3)$ & $2(9.5)$ \\
\hline \multicolumn{4}{|c|}{ Previous caesarean sections (multiparous women, $n=477$ ) } \\
\hline No & $180(65.7)$ & $132(71.7)$ & $15(78.9)$ \\
\hline Yes & $52(19.0)$ & $31(16.9)$ & $3(15.8)$ \\
\hline Not known & $42(15.3)$ & $21(11.4)$ & $1(5.3)$ \\
\hline \multicolumn{4}{|c|}{ Previous pregnancy problems* } \\
\hline No & $267(40.7)$ & $168(50.9)$ & $11(52.4)$ \\
\hline Yes & $44(6.7)$ & $20(6.1)$ & $3(14.3)$ \\
\hline Not known & $345(52.6)$ & $142(43.0)$ & 7 (33.3) \\
\hline \multicolumn{4}{|c|}{ Anaemia during previous pregnancy* } \\
\hline No & $203(30.9)$ & $108(32.7)$ & $3(14.3)$ \\
\hline Yes & $7(1.1)$ & $22(6.7)$ & $10(47.6)$ \\
\hline Not known & $446(68.0)$ & $200(60.6)$ & $8(38.1)$ \\
\hline \multicolumn{4}{|c|}{ Pre-existing medical problems } \\
\hline No & $637(97.1)$ & $313(94.8)$ & $19(90.5)$ \\
\hline Yes & $18(2.7)$ & $17(5.2)$ & $2(9.5)$ \\
\hline Not known & $1(0.2)$ & $0(0)$ & $0(0)$ \\
\hline \multicolumn{4}{|l|}{ Index pregnancy } \\
\hline \multicolumn{4}{|l|}{ Multiple pregnancy } \\
\hline No & $647(98.6)$ & $321(97.3)$ & $21(100)$ \\
\hline Yes & $9(1.4)$ & $9(2.7)$ & $0(0)$ \\
\hline Not known & 0 & 0 & 0 \\
\hline \multicolumn{4}{|c|}{ Number of antenatal check-ups* } \\
\hline$\geq 4$ & $335(51.1)$ & $183(55.5)$ & $9(42.9)$ \\
\hline At least 1 but $<4$ & $232(35.4)$ & $96(29.1)$ & 7 (33.3) \\
\hline
\end{tabular}

Table 1 Continued

\begin{tabular}{|c|c|c|c|}
\hline \multirow[b]{2}{*}{$\begin{array}{l}\text { Characteristics } \\
\text { ( } \mathrm{N}=1007 \text {, except } \\
\text { where specified) }\end{array}$} & \multicolumn{3}{|c|}{ Maternal anaemia } \\
\hline & $\begin{array}{l}\text { Normal } \\
\text { haemoglobin/ } \\
\text { mild, } n=656 \\
\text { Frequency } \\
(\%)\end{array}$ & $\begin{array}{l}\text { Moderate, } \\
\mathrm{n}=330 \\
\text { Frequency } \\
(\%)\end{array}$ & $\begin{array}{l}\text { Severe, } \\
\mathrm{n}=21 \\
\text { Frequency } \\
(\%)\end{array}$ \\
\hline None & $46(7.0)$ & $38(11.5)$ & $5(23.8)$ \\
\hline Not known & $43(6.5)$ & $13(3.9)$ & $0(0)$ \\
\hline \multicolumn{4}{|c|}{ Received folic acid tablets } \\
\hline No & $160(24.4)$ & $88(26.7)$ & 9 (42.9) \\
\hline Yes & $495(75.4)$ & 242 (73.3) & $12(57.1)$ \\
\hline Not known & $1(0.2)$ & $0(0)$ & $0(0)$ \\
\hline
\end{tabular}

Received any treatment (women diagnosed with anaemia, $\mathrm{n}=499)^{\star}$

$\begin{array}{lcrc}\text { No } & 155(23.6) & 107(32.4) & 3(14.3) \\ \text { Yes } & 44(6.7) & 81(24.6) & 16(76.2) \\ \text { Not known } & 457(69.7) & 142(43.0) & 2(9.5)\end{array}$

Infection during pregnancy (malaria/UTI/helminthic infection)*

$\begin{array}{lccc}\text { No } & 602(91.8) & 282(85.5) & 10(47.6) \\ \text { Yes } & 17(2.6) & 13(3.9) & 3(14.3) \\ \text { Not known } & 37(5.6) & 35(10.6) & 8(38.1)\end{array}$

$37(5.6) \quad 35(10.6) \quad 8(38.1)$

Placental problems during index pregnancy

$\begin{array}{lccc}\text { No } & 646(98.5) & 323(97.9) & 21(100) \\ \text { Yes } & 9(1.4) & 7(2.1) & 0(0)\end{array}$

Not known $\quad 1(0.1) \quad 0(0) \quad 0(0)$

Mode of delivery ${ }^{*}$

Spontaneous $289(44.1) \quad 202(61.2) \quad 14(66.7)$

vaginal

\begin{tabular}{lrrl} 
Ventouse & $6(0.9)$ & $1(0.3)$ & $0(0)$ \\
Forceps & $12(1.8)$ & $3(0.9)$ & $1(4.7)$ \\
Breech & $3(0.5)$ & $1(0.3)$ & $0(0)$ \\
$\begin{array}{l}\text { Elective } \\
\text { caesarean } \\
\text { section }\end{array}$ & $72(11.0)$ & $31(9.4)$ & $0(0)$ \\
$\begin{array}{l}\text { Emergency } \\
\text { caesarean } \\
\text { section }\end{array}$ & $273(41.6)$ & $91(27.6)$ & $6(28.6)$ \\
\hline
\end{tabular}

Not known $\quad 1(0.1) \quad 1(0.3) \quad 0(0)$

Delivery induced

$\begin{array}{lccc}\text { No } & 567(86.4) & 287(87.0) & 17(81.0) \\ \text { Yes } & 60(9.2) & 22(6.7) & 3(14.3) \\ \text { Not known } & 29(4.4) & 21(6.3) & 1(4.7) \\ \text { Sociodemographic factors } & & \end{array}$

Caste/social class*

\begin{tabular}{lccl} 
Schedule caste & $68(10.4)$ & $26(7.9)$ & $2(9.5)$ \\
$\begin{array}{l}\text { Schedule tribe } \\
\begin{array}{l}\text { Other backward } \\
\text { classes }\end{array}\end{array}$ & $75(12.3)$ & $61(18.5)$ & $6(28.6)$ \\
$\begin{array}{l}\text { General } \\
\text { Not known }\end{array}$ & $531(65.7)$ & $186(56.4)$ & $7(33.3)$ \\
\hline
\end{tabular}

Continued 
Table 1 Continued

\begin{tabular}{|c|c|c|c|}
\hline \multirow[b]{2}{*}{$\begin{array}{l}\text { Characteristics } \\
\text { ( } N=1007 \text {, except } \\
\text { where specified) }\end{array}$} & \multicolumn{3}{|c|}{ Maternal anaemia } \\
\hline & $\begin{array}{l}\text { Normal } \\
\text { haemoglobin/ } \\
\text { mild, } \mathrm{n}=656 \\
\text { Frequency } \\
(\%)\end{array}$ & $\begin{array}{l}\text { Moderate, } \\
\mathrm{n}=330 \\
\text { Frequency } \\
(\%)\end{array}$ & $\begin{array}{l}\text { Severe, } \\
\mathrm{n}=21 \\
\text { Frequency } \\
(\%)\end{array}$ \\
\hline \multicolumn{4}{|l|}{ Religion* } \\
\hline Hindu & $456(69.5)$ & $236(71.5)$ & $16(76.2)$ \\
\hline Muslim & 190 (28.9) & $66(20.0)$ & $2(9.5)$ \\
\hline Others & $5(0.8)$ & $8(2.4)$ & $2(9.5)$ \\
\hline Not known & $5(0.8)$ & $20(6.1)$ & $1(4.8)$ \\
\hline \multicolumn{4}{|l|}{ Residence } \\
\hline Rural & $560(85.3)$ & $282(85.5)$ & $19(90.5)$ \\
\hline Urban & $95(14.5)$ & $48(14.5)$ & $2(9.5)$ \\
\hline Not known & $1(0.2)$ & $0(0)$ & $0(0)$ \\
\hline \multicolumn{4}{|c|}{ Belongs to BPL household* } \\
\hline No & $309(47.1)$ & $132(40.0)$ & $6(28.6)$ \\
\hline Yes & $286(43.6)$ & $143(43.3)$ & $12(57.1)$ \\
\hline Not known & $61(9.3)$ & 55 (16.7) & $3(14.3)$ \\
\hline \multicolumn{4}{|c|}{ Husband in paid employment } \\
\hline Employed & $594(90.6)$ & $300(90.9)$ & $18(85.7)$ \\
\hline Unemployed & $14(2.1)$ & $6(1.8)$ & $0(0)$ \\
\hline Not known & $48(7.3)$ & $24(7.3)$ & $3(14.3)$ \\
\hline \multicolumn{4}{|c|}{ Women in paid employment* } \\
\hline No & $571(87.0)$ & $263(79.7)$ & $14(66.7)$ \\
\hline Yes & $33(5.0)$ & $31(9.4)$ & $6(28.6)$ \\
\hline Not known & $52(7.9)$ & $36(10.9)$ & $1(4.7)$ \\
\hline \multicolumn{4}{|c|}{ Husband tea garden worker* } \\
\hline No & $562(85.7)$ & 261 (79.1) & $12(57.1)$ \\
\hline Yes & $46(7.0)$ & 45 (13.6) & $6(28.6)$ \\
\hline Not known & $48(7.3)$ & $24(7.3)$ & $3(14.3)$ \\
\hline
\end{tabular}

${ }^{*} \mathrm{p}<0.05$ for $\chi^{2}$ test for difference in proportion.

$\mathrm{BMI}$, body mass index; BPL, below poverty line; UTI, urinary tract infection.

The study showed that after adjusting for other risk factors, women with severe anaemia were at a significantly higher risk of PPH, giving birth to low birthweight and small-for-gestational age babies, and having a baby who died in the perinatal period. The odds of these adverse outcomes were also higher among women with moderate anaemia, but only the association with low birth weight was statistically significant. Importantly, the risk of PPH increased 17-fold among women with moderate-severe anaemia who underwent induction of labour.

\section{Limitations of this study}

This was a retrospective cohort study based on information collected from the hospital records of pregnant women. There are known issues related to estimation of blood loss in the peripartum period and after delivery through observation alone; therefore, we cannot ignore the possibility of misclassification. We were also not able to grade the severity of PPH. As discussed above, the hospital notes did not have records of the $\mathrm{Hb}$ level at different gestational periods; thus, the effects of anaemia in relation to the different gestational periods could not be ascertained. Another inherent limitation of collecting data from hospital records is a high proportion of missing data, which was evident in our study. However, the estimated ORs using complete case analysis and sensitivity analyses were not substantively different from the outputs of the main models.

\section{Findings in relation to other studies}

A number of studies in India and in other low and middle income countries (LMICs) have shown that anaemia during pregnancy is associated with increased risk of $\mathrm{PPH}^{6}{ }^{6} \quad{ }^{21}$ low birthweight ${ }^{4}{ }^{5}{ }^{21}$ and small-for-gestational age babies. ${ }^{41}$ Our results, in relation to the adverse neonatal outcomes, are comparable to the other study in Assam conducted in one hospital $(n=421) .{ }^{4}$ Studies from other countries show varying results when examining the association between maternal anaemia on the risk of perinatal death. One study in Pakistan found maternal anaemia to be associated with increased risk of stillbirth, ${ }^{22}$ but another in China showed that a $\mathrm{Hb}$ level $<9 \mathrm{~g} / \mathrm{dL}$ in the third trimester was associated with a reduced risk of stillbirth and maternal anaemia was not associated with neonatal death. ${ }^{23} \mathrm{~A}$ study that used National Maternal and Infant Health Survey data in the USA found moderate anaemia to be associated with an increased risk of stillbirth among nonblack women, but found no statistically significant association among black women. ${ }^{24}$

Individual associations of infections during pregnancy and maternal anaemia with adverse maternal and fetal outcomes have been shown by several studies. ${ }^{5} 61012$ It is known that there is a causal relationship between infections and anaemia during pregnancy. ${ }^{11}$ We found a significant additive effect of infection and moderatesevere anaemia on increased risk of $\mathrm{PPH}$, but this was not observed for the infant outcomes.

We observed a 17-fold increased risk of PPH among pregnant women with moderate-severe anaemia who underwent induction of labour. A few small studies have suggested that women with severe anaemia are more likely to have uterine atony due to impaired transport of oxygen and $\mathrm{Hb}$ to the uterus, ${ }^{621}$ but there is no strong evidence. This could be a possible explanation for the increased risk of PPH observed among pregnant women with moderatesevere anaemia who underwent induction of labour in this study, but it is also possible that other mechanisms exist.

\section{Implications and future research}

We found a high prevalence of iron deficiency anaemia among pregnant women in Assam which highlights that this is an important public health problem. Maternal anaemia was associated with increased risks of $\mathrm{PPH}$, low birthweight, small-for-gestational age babies and 
Table 2 Association between maternal anaemia and maternal and infant outcomes

$\begin{array}{llll}\begin{array}{l}\text { Outcome } \\ \text { present, } \mathbf{n}(\%)\end{array} & \begin{array}{l}\text { Outcome } \\ \text { absent, } \mathbf{n}(\%)\end{array} & \begin{array}{l}\text { Unadjusted OR } \\ (95 \% \text { Robust Cl) }\end{array} & \begin{array}{l}\text { Adjusted OR } \\ (95 \% \text { Robust Cl) }\end{array}\end{array}$

Postpartum haemorrhage $(n=1006)$

Anaemia

\begin{tabular}{|c|c|c|c|c|}
\hline Normal/mild ( $\geq 10 \mathrm{~g} / \mathrm{dL})$ & $15(2.3)$ & $641(97.7)$ & 1 (ref) & 1 (ref) \\
\hline Moderate (7-9.9 g/dL) & $13(3.9)$ & $316(96.1)$ & 1.76 (0.79 to 3.90$)$ & 1.50 (0.80 to 2.80$)$ \\
\hline Severe $(<7 \mathrm{~g} / \mathrm{dL})$ & $5(23.8)$ & $16(76.2)$ & 13.35 (4.88 to 36.54$)$ & 9.45 (2.62 to 34.05$)$ \\
\hline \multicolumn{5}{|c|}{ Anaemia and/or induction of labour } \\
\hline None & $12(2.1)$ & 555 (97.9) & 1 (ref) & 1 (ref) \\
\hline Either & $14(3.9)$ & $350(96.1)$ & 1.85 (0.91 to 3.75$)$ & 1.76 (0.96 to 3.22$)$ \\
\hline Both & $5(20.0)$ & $20(80.0)$ & 11.56 (2.38 to 56.13 ) & 17.39 (3.73 to 80.97$)$ \\
\hline Missing & $2(4.0)$ & $48(96.0)$ & 1.93 (0.95 to 3.89 ) & 2.14 (1.15 to 3.99$)$ \\
\hline \multicolumn{5}{|l|}{ Anaemia and/or infection } \\
\hline None & $14(2.3)$ & $588(97.7)$ & 1 (ref) & 1 (ref) \\
\hline Either & $12(3.9)$ & $296(96.1)$ & 1.70 (1.06 to 2.75$)$ & 1.39 (0.89 to 2.15$)$ \\
\hline Both & $4(25.0)$ & $12(75.0)$ & $14.00(1.66$ to 118.07$)$ & 18.80 (3.57 to 98.93$)$ \\
\hline Missing & $3(3.8)$ & 77 (96.2) & 1.64 (0.31 to 8.56$)$ & $2.64(0.21$ to 33.45$)$ \\
\hline
\end{tabular}

Low birth weight (singleton liveborn only, $n=966$ )

Anaemia

\begin{tabular}{lrrrr} 
Normal/mild $(\geq 10 \mathrm{~g} / \mathrm{dL})$ & $160(25.2)$ & $474(74.8)$ & 1 (ref) & 1 (ref) \\
\hline Moderate $(7-9.9 \mathrm{~g} / \mathrm{dL})$ & $91(29.2)$ & $221(70.8)$ & $1.22(0.94$ to 1.58$)$ & $1.26(1.04$ to 1.53$)$ \\
$\begin{array}{l}\text { Severe }(<7 \mathrm{~g} / \mathrm{dL}) \\
\text { Anaemia and/or infection }\end{array}$ & $12(60.0)$ & $8(40.0)$ & $4.44(1.75$ to 11.28$)$ & $6.19(1.44$ to 26.71$)$ \\
None & $142(24.4)$ & $440(75.6)$ & 1 (ref) & 1 (ref) \\
Either & $86(29.3)$ & $208(70.7)$ & $1.28(0.99$ to 1.65$)$ & $1.27(0.99$ to 1.65$)$ \\
Both & $3(21.4)$ & $11(78.6)$ & $0.85(0.37$ to 1.95$)$ & $1.21(0.40$ to 3.59$)$ \\
Missing & $32(42.1)$ & $44(57.9)$ & $2.25(1.18$ to 4.29$)$ & $1.32(0.70$ to 2.49$)$
\end{tabular}

Small-for-gestational age (singleton liveborn, $n=881$ )

Anaemia

\begin{tabular}{lrrrr} 
Normal/mild $(\geq 10 \mathrm{~g} / \mathrm{dL})$ & $251(43.7)$ & $323(56.3)$ & 1 (ref) & 1 (ref) \\
\hline Moderate $(7-9.9 \mathrm{~g} / \mathrm{dL})$ & $143(49.5)$ & $146(50.5)$ & $1.26(0.82$ to 1.94$)$ & $1.25(0.91$ to 1.73$)$ \\
\hline $\begin{array}{l}\text { Severe }(<7 \mathrm{~g} / \mathrm{dL}) \\
\text { Anaemia and/or infection }\end{array}$ & $15(83.3)$ & $3(16.7)$ & $6.43(0.87$ to 47.39$)$ & $8.72(1.66$ to 45.67$)$ \\
\hline None & $228(43.1)$ & $301(56.9)$ & 1 (ref) & 1 (ref) \\
Either & $134(49.8)$ & $135(50.2)$ & $1.31(0.83$ to 2.07$)$ & $1.20(0.80$ to 1.80$)$ \\
Both & $6(42.9)$ & $8(57.1)$ & $0.99(0.50$ to 1.98$)$ & $1.40(0.67$ to 2.93$)$ \\
Missing & $41(59.4)$ & $28(40.6)$ & $1.93(1.26$ to 2.97$)$ & $1.35(0.87$ to 2.11$)$
\end{tabular}

Perinatal deaths (singleton pregnancies, $n=987$ )

Anaemia

$\begin{array}{lcccc}\text { Normal/mild }(\geq 10 \mathrm{~g} / \mathrm{dL}) & 18(2.8) & 628(97.2) & 1 \text { (ref) } & 1 \text { (ref) } \\ \text { Moderate }(7-9.9 \mathrm{~g} / \mathrm{dL}) & 10(3.1) & 310(96.9) & 1.13(0.65 \text { to } 1.96) & 1.18(0.64 \text { to } 2.19) \\ \text { Severe }(<7 \mathrm{~g} / \mathrm{dL}) & 4(19.1) & 17(80.9) & 8.21(3.20 \text { to } 21.09) & 16.42(4.38 \text { to } 61.55)\end{array}$

The final multivariable models were adjusted for the following risk factors: caste, religion, residence, below poverty line status, women's employment status, tea garden worker, parity, body mass index, maternal age, previous caesarean section, previous pregnancy problems, pre-existing medical problems, multiple pregnancies, number of antenatal visits, whether folic acid tablets were received, and mode of delivery. Mode of delivery was not included in the infant outcomes model as this is not likely to be causally associated. Gestational age was included in the low birth weight model.

perinatal death. Clearly, the best approach would be to prevent anaemia or to treat it during the antenatal period, but the Annual Health Survey showed that only
$23 \%$ of the pregnant women in Assam consumed the complete course of iron-folic acid tablets in 2012-2013 (a slight improvement from $15.3 \%$ in 2010-2011). ${ }^{25} \mathrm{~A}$ 
large number of pregnant women in India present with severe anaemia either at the point of delivery or in the third trimester. ${ }^{26} 27$ In this study, $62 \%$ of the women with severe anaemia had low $\mathrm{Hb}$ levels during the third trimester of pregnancy when there is little scope for prevention or iron treatment.

At present, there is no clear guidance with regard to how women with severe anaemia should be managed during labour and delivery. The WHO guidelines on induction of labour do not provide any recommendation with regard to whether induction of labour should be carried out in women with severe anaemia; ${ }^{28}$ nor do the guidelines on management of anaemia make recommendations for management of women with moderate-severe anaemia during labour and delivery. ${ }^{17}$ Considering the high prevalence $(35 \%)$ of moderate-severe anaemia among pregnant women in the study population and in several LMICs (an estimated $42 \%$ of pregnant women suffer from anaemia globally ${ }^{29}$ ), and its association with PPH and high risk of maternal death, further consideration needs to be given to generating evidence on the appropriate management of pregnant women with moderate-severe anaemia during the peripartum period to prevent maternal morbidity and mortality.

By successfully conducting this pilot study, we were able to demonstrate that the IndOSS-Assam platform can be used to conduct epidemiological research. A number of studies will be undertaken through this platform in the near future to test the hypotheses generated in this study, and to examine the risk factors, management and outcomes of other pregnancy complications in order to improve care.

\section{Handling editor Seye Abimbola}

Contributors MN designed the study, trained the field staff, conducted literature searches, planned and carried out the data analysis, interpreted the data, and wrote the first draft of the manuscript. MKC designed the study, trained the field staff, supervised data collection and data entry, and edited the manuscript. SSC designed the study, trained the field staff, supervised data collection and data entry, and edited the manuscript. SDK designed the study, trained the field staff, and edited the manuscript. UCS designed the study, trained the field staff, supervised data collection, and edited the manuscript. PW designed the study, and edited the manuscript. MK designed the study, contributed to the data analysis plan, data interpretation, and to the writing of the manuscript.

Funding This study was funded by the John Fell Oxford University Press (OUP) Research Fund, PRAC/JF/131/124; and by the Srimanta Sankaradeva University of Health Sciences, Assam. MK is funded by a National Institute for Health Research (NIHR) Research Professorship.

Disclaimer The funders had no role in study design, data collection and analysis, decision to publish, or preparation of the manuscript.

Competing interests None declared.

Ethics approval The IndOSS-Assam feasibility study, of which this retrospective study was a part, was approved by the Institutional Ethics Committee of Srimanta Sankaradeva University of Health Sciences (No SSUHS/Ethics/2014/1, dated 27 June 2014); the Health Ministry's Screening Committee, Indian Council of Medical Research (No 5/7/12 12/14-RCH, dated 25 September 2014) and the University of Oxford's Oxford Tropical Research Ethics Committee (OxTRTEC Reference 57-14).
Provenance and peer review Not commissioned; externally peer reviewed.

Data sharing statement No additional data are available

Open Access This is an Open Access article distributed in accordance with the Creative Commons Attribution Non Commercial (CC BY-NC 4.0) license, which permits others to distribute, remix, adapt, build upon this work noncommercially, and license their derivative works on different terms, provided the original work is properly cited and the use is non-commercial. See: http:// creativecommons.org/licenses/by-nc/4.0/

\section{REFERENCES}

1. Office of Registrar General India. Special bulletin on maternal mortality in India 2010-12: sample registration system. New Delhi: Office of Registrar General, India-Vital Statistics Division, 2013.

2. Office of Registrar General India. SRS Bulletin October 2012: sample registration system. New Delhi: Office of Registrar General, India-Vital Statistics Division, 2012.

3. International Institute for Population Sciences (IIPS) and Macro International. National Family Health Survey (NFHS-3), 2005-06. India: Key Findings Mumbai: IIPS, 2007.

4. Bora R, Sable C, Wolfson J, et al. Prevalence of anemia in pregnant women and its effect on neonatal outcomes in Northeast India. J Matern Fetal Neonatal Med 2014;27:887-91.

5. Haider BA, Olofin I, Wang M, et al., Nutrition Impact Model Study Group (anaemia). Anaemia, prenatal iron use, and risk of adverse pregnancy outcomes: systematic review and meta-analysis. BMJ 2013;346:f3443.

6. Kavle JA, Stoltzfus RJ, Witter F, et al. Association between anaemia during pregnancy and blood loss at and after delivery among women with vaginal births in Pemba Island, Zanzibar, Tanzania. J Health Popul Nutr 2008;26:232-40.

7. Montgomery AL, Ram U, Kumar R, et al. Maternal mortality in India: causes and healthcare service use based on a nationally representative survey. PLOS ONE 2014;9:e83331.

8. Center for Reproductive Rights. Maternal mortality in India: using International and Constitutional Law to promote accountability and change. New York: Center for Reproductive Rights, 2008.

9. Phukan RK, Mahanta J. A study of neonatal deaths in the tea gardens of Dibrugarh district of upper Assam. J Indian Med Assoc 1998:96:333-4, 37.

10. McClure EM, Goldenberg RL, Dent AE, et al. A systematic review of the impact of malaria prevention in pregnancy on low birth weight and maternal anemia. Int $J$ Gynaecol Obstet 2013;121:103-9.

11. Giles C, Brown JA. Urinary infection and anaemia in pregnancy. BMJ 1962;2:10-13.

12. Brooker S, Hotez PJ, Bundy DA. Hookworm-related anaemia among pregnant women: a systematic review. PLoS Negl Trop Dis 2008;2: e291.

13. Brinsden PR, Clark AD. Postpartum haemorrhage after induced and spontaneous labour. BMJ 1978;2:855-6.

14. Khireddine I, Le Ray C, Dupont C, et al. Induction of labor and risk of postpartum hemorrhage in low risk parturients. PLOS ONE 2013;8:e54858.

15. Nair M, Choudhury MK, Choudhury SS, et al. IndOSS-Assam: Investigating the feasibility of introducing a simple maternal morbidity surveillance and research system in Assam, India. BMJ Global Health 2016;1:e000024.

16. Knight $M$, Lindquist $A$. The UK Obstetric Surveillance System: impact on patient safety. Best Pract Res Clin Obstet Gynaecol 2013;27:621-30.

17. WHO, UNICEF, UNU. Iron deficiency anaemia: assessment, prevention and control, a guide for programme managers. 2001. http://www.who.int/nutrition/publications/micronutrients/anaemia iron_deficiency/WHO_NHD_01.3/en/index.html (accessed 11 Apr 2014).

18. World Health Organisation. WHO recommendations for the prevention and treatment of postpartum haemorrhage. Italy: World Health Organisation, 2012.

19. INTERGROWTH-21st. INTERGROWTH-21st Newborn Size Application Tool. Secondary INTERGROWTH-21st Newborn Size Application Tool. https://intergrowth21.tghn.org/global-perinatalpackage/intergrowth-21st-comparison-application/

20. North Eastern Social Research Centre. Positioning children in Assam state budget. Guwahati: North Eastern Social Research Centre.

21. Malhotra M, Sharma JB, Batra S, et al. Maternal and perinatal outcome in varying degrees of anemia. Int J Gynaecol Obstet 
2002;79:93-100.

22. Lone FW, Qureshi RN, Emmanuel F. Maternal anaemia and its impact on perinatal outcome in a tertiary care hospital in Pakistan. East Mediterr Health J 2004;10:801-7.

23. Zhang Q, Ananth CV, Rhoads GG, et al. The impact of maternal anemia on perinatal mortality: a population-based, prospective cohort study in China. Ann Epidemiol 2009;19:793-9.

24. Tomashek KM, Ananth CV, Cogswell ME. Risk of stillbirth in relation to maternal haemoglobin concentration during pregnancy. Matern Child Nutr 2006;2:19-28.

25. Office of Registrar General and Census Commissioner India. Annual Health Survey 2012-13: Fact sheet.
New Delhi: Ministry of Home Affairs, Government of India, 2014.

26. Chhabra S, Sirohi R. Trends in maternal mortality due to haemorrhage: two decades of Indian rural observations. J Obstet Gynaecol 2004;24:40-3.

27. Rohilla M, Raveendran A, Dhaliwal L, et al. Severe anaemia in pregnancy: a tertiary hospital experience from Northern India. J Obstet Gynaecol 2010;30:694-6.

28. World Health Organisation. WHO recommendations for induction of labour. Geneva: World Health Organisation, 2011.

29. de Benoist B, McLean E, Egli I, et al, eds. Worldwide prevalence of anaemia 1993-2005: WHO global database on anaemia. Geneva: World Health Organisation, 2008. 